\title{
Preliminary exploration on the therapeutic effect of AGGF1 in mice with lower limb ischemia and corresponding molecular mechanism.
}

\author{
Baohua Sun ${ }^{1,2}$, Fangda Li ${ }^{1}$, Jiang Shao ${ }^{1}$, Bao Liu' ${ }^{1}$, Yu Chen ${ }^{1}$, Changwei Liu ${ }^{1}$, Yuehong Zheng1* \\ ${ }^{1}$ Department of Vascular Surgery, Peking Union Medical College Hospital, Peking Union Medical College and Chinese \\ Academy of Medical Sciences, Beijing, PR China \\ ${ }^{2}$ Department of Vascular Surgery, the Fourth People's Hospital of Jinan City, Jinan, PR China
}

\begin{abstract}
Objective: This study aimed to observe the therapeutic effect of angiogenic factor with G-patch and FHA domain 1 (AGGF1) in mice with lower limb ischemia and determine the corresponding molecular mechanism.

Methods: A total of $40 \mathrm{C} 57 \mathrm{BL} / 6$ male mice were selected. 32 mice were chosen to establish the lower limb ischemia model and divided into the low-dose, middle-dose, high-dose, and model groups. The remaining 8 mice comprised the sham-operation group and underwent separation of the left arteria femoralis and arteria iliaca externa (same with the model group). AGGF1 was injected once every day for 4 weeks. Tissue necrosis, dyskinesia scores, and recovery percentage of lower limb bloodstream at $\mathbf{1}$, 2, and 4 weeks after AGGF1 injection were compared. All mice were killed after 4 weeks of treatment. AGGF1, hypoxia-inducible factor $1 \alpha(\mathrm{HIF}-1 \alpha)$, and vascular endothelial growth factor (VEGF) mRNA and protein levels in the musculus gastrocnemius at the operation side were measured and compared.

Results: Tissue necrosis and dyskinesia scores at 1, 2 and 4 weeks after AGGF1 injection and AGGF1, HIF-1 $\alpha$, and VEGF mRNA and protein levels in the musculus gastrocnemius of different groups were compared. The sham-operation group achieved the lowest values, followed by the middle-dose, highdose, low-dose, and model groups successively. Statistically significant differences between any two groups were found $(\mathbf{P}<\mathbf{0 . 0 5})$. Intra-group comparison revealed a slight change in the tissue necrosis score of the sham-operation group $(\mathbf{P}>\mathbf{0 . 0 5})$. The dyskinesia scores of the sham-operation group and the three dose groups sharply dropped as time passed $(\mathbf{P}<\mathbf{0 . 0 5})$, whereas those of the model group dramatically increased $(\mathbf{P}<\mathbf{0 . 0 5})$.

Conclusions: AGGF1 $(2 \mu \mathrm{g} / \mathrm{mL})$ can improve tissue necrosis and dyskinesia and accelerate lower limb bloodstream recovery of mice with lower limb ischemia. The mechanism is speculated to be related to an upregulated expression of AGGF1, HIF-1 $\alpha$, and VEGF mRNA and proteins.
\end{abstract}

Keywords: Lower limb ischemia, AGGF1, VEGF, HIF-1 $\alpha$.

Accepted on February 20, 2018

\section{Introduction}

Lower limb ischemia is a series of vascular disease caused by a dysfunction induced by arteriostenosis, embolism, or arterial aneurysm [1]. Limb swelling, pain, numbness, and claudication are its main symptoms. Patients with serious lower limb ischemia suffer from gangrene and other typical clinical features [2]. Gene therapy is a new therapeutic method for this disease. Angiogenic factor with G-patch and FHA domain 1 ( $A G G F 1)$ gene therapy exhibits outstanding clinical effect against peripheral arterial disease [3]. However, few studies on the molecular mechanism of AGGF1 in diseases with lower limb ischemia have been reported. Thus, in this study, we observed the therapeutic effect of AGGF1 in mice with lower limb ischemia and explored the corresponding molecular mechanism, aiming to provide new insights into the clinical therapy of diseases with lower limb ischemia.

\section{Information and Methods}

\section{Materials}

AGGF1 eukaryotic expression of pEGFP-N1 carrier, RNA extraction kit, Pierce BCA protein quantitative analysis kit, human anti-mouse VG5Q (AGGF1) polyclonal antibody, rat anti-mouse hypoxia-inducible factor $1 \alpha$ (HIF-1 $\alpha)$ monoclonal antibody (primary antibody), cattle anti-mouse HIF-1 $\alpha$ monoclonal antibody (secondary antibody), rabbit anti-mouse vascular endothelial growth factor (VEGF) monoclonal antibody (primary antibody), goat anti-rabbit VEGF polyclonal antibody (secondary antibody), PeriFlux 5000 laser Doppler 
flowmeter, PCR instrument, electrophoresis apparatus, and gelimaging system were used as materials.

\section{Methods}

Modeling and grouping: A total of 40 C57BL/6 male mice were collected and anesthetized with an intraperitoneal injection of pentobarbital sodium ( $50 \mathrm{mg} / \mathrm{kg}$ of body weight). The left rear limb was shaved and disinfected. An incision was made at the groin, and blunt dissection of the muscle was performed. The arteria femoralis and arteria iliaca externa were found, and the upper end of two arteries was ligated. The modeling was considered successful if the blood flow rate on the operated limb was reduced to $<1 / 10$ of that before the operation according to Doppler flowmeter analysis. Mice with successful modeling were divided into four groups: low-dose, middle-dose, high-dose, and model groups, with eight mice each. The remaining eight mice, which were subjected to the separation of left arteria femoralis and arteria iliaca externa, comprised the sham-operation group.

Physiological situation assessment of mice: Tissue necrosis and dyskinesia of different groups were assessed at 1,2 and 4 weeks after AGGF1 injection. The following evaluation standards for tissue necrosis were used: 0 for no tissue necrosis, 1 for single toe necrosis, 2 for 2 (or more) toes with necrosis, 3 for foot necrosis, 4 for lower limb necrosis, and 5 for leg dialysis. For dyskinesia, the following evaluation standards were used: 0 for no dyskinesia, 1 for no toe reaction but with tread reaction, 2 for no toe and tread reaction, and 3 for off-limb walking.

Local blood flow test of mice posterior limb using laser Doppler: Pentobarbital sodium was intraperitoneally injected to anesthetize mice. After the mice were positioned lying on the back and fixed, two lower limb regions were scanned using the laser Doppler blood flowmeter. The average laser Doppler blood flow values of lower limbs of mice were analyzed by Moor Instruments. The percentage of blood flow recovery of lower limbs was calculated. It is equal to the blood perfusion ratio between the operation side and healthy side.

\section{Statistical analysis}

All data were processed and analyzed by SPSS16.0. Measurement data were expressed as mean \pm standard deviation $(\overline{\mathrm{x}} \pm \mathrm{s})$ and examined by t-test. Repeated sample and multi-sample measurement data were analyzed using ANOVA and one-way ANOVA, respectively. $\mathrm{P}<0.05$ indicates statistically significant difference.

\section{Results}

\section{Tissue necrosis and dyskinesia scores}

Tissue necrosis and dyskinesia scores of mice showed statistically significant differences among different groups at different time points and interaction comparison $(\mathrm{P}<0.05)$. They were compared after 1, 2 and 4 weeks. The shamoperation group achieved the lowest scores, followed by the middle-dose, high-dose, low-dose, and model groups successively. Statistically significant differences between any two groups were observed $(\mathrm{P}<0.05)$. Intra-group comparison revealed a slight change in the tissue necrosis score of the sham-operation group $(\mathrm{P}>0.05)$. The dyskinesia score of the sham-operation and the three dose groups sharply dropped as time passed $(\mathrm{P}<0.05)$, whereas that of the model group significantly increased $(\mathrm{P}<0.05)$. The results are shown in Table 1.

Table 1. Comparison of tissue necrosis and dyskinesia scores among different groups $(\bar{x} \pm s$, scores).

\begin{tabular}{|c|c|c|c|c|c|c|}
\hline \multirow[t]{2}{*}{ Groups } & \multicolumn{3}{|l|}{ Tissue necrosis } & \multicolumn{3}{|l|}{ Dyskinesia } \\
\hline & 1 week & 2 weeks & 4 weeks & 1 week & 2 weeks & 4 weeks \\
\hline Sham-operation & $0.55 \pm 0.10$ & $0.49 \pm 0.11$ & $0.45 \pm 0.09$ & $1.35 \pm 0.11$ & $0.89 \pm 0.06^{\mathrm{e}}$ & $0.53 \pm 0.04^{\mathrm{ef}}$ \\
\hline Model & $2.45 \pm 0.13^{a}$ & $2.67 \pm 0.15^{\mathrm{ae}}$ & $3.42 \pm 0.23^{\text {aef }}$ & $2.36 \pm 0.15^{a}$ & $2.58 \pm 0.14^{\mathrm{ae}}$ & $2.77 \pm 0.27^{\text {aef }}$ \\
\hline Low-dose & $2.22 \pm 0.20^{\mathrm{ab}}$ & $1.95 \pm 0.33^{\text {abe }}$ & $1.57 \pm 0.17^{\text {abef }}$ & $2.17 \pm 0.20^{\mathrm{ab}}$ & $1.83 \pm 0.18^{\mathrm{abe}}$ & $1.46 \pm 0.13^{\text {abef }}$ \\
\hline Middle-dose & $1.60 \pm 0.12^{\mathrm{abc}}$ & $1.37 \pm 0.11^{\mathrm{abce}}$ & $0.93 \pm 0.06^{\text {abcef }}$ & $1.43 \pm 0.14^{\mathrm{abc}}$ & $1.10 \pm 0.07^{\mathrm{abce}}$ & $0.82 \pm 0.05^{\text {abcef }}$ \\
\hline High-dose & $2.08 \pm 0.09^{a b c d}$ & $1.77 \pm 0.06^{\mathrm{abcde}}$ & $1.30 \pm 0.11^{\mathrm{abcdef}}$ & $1.87 \pm 0.06^{\mathrm{abcd}}$ & $1.46 \pm 0.12^{\mathrm{abcde}}$ & $1.03 \pm 0.07^{\text {abcdef }}$ \\
\hline $\mathrm{F}$ & $F_{\text {groups }}=26.579$ & $F_{\text {time }}=18.37$ & $F_{\text {interaction }}=21.379$ & $F_{\text {groups }}=29.008$ & $F_{\text {time }}=20.100$ & $F_{\text {interaction }}=22.379$ \\
\hline$P$ & $P_{\text {groups }}=0.000$ & $P_{\text {time }}=0.000$ & $P_{\text {interaction }}=0.000$ & $P_{\text {groups }}=0.000$ & $P_{\text {time }}=0.000$ & $P_{\text {interaction }}=0.000$ \\
\hline
\end{tabular}

Note: Compared with sham-operation group, aP<0.05; Compared with model group, ${ }^{\mathrm{b}} \mathrm{P}<0.05$; Compared with low-dose group, ${ }^{\mathrm{c}} \mathrm{P}<0.05$; Compared with middle-dose, d $\mathrm{P}<0.05$; Compared with 1 week, $\mathrm{P}<0.05$; Compared with 2 week, $\mathrm{f} P<0.05$.

Table 2. Comparison of recovery percentage of lower limb bloodstream among different groups $(\bar{x} \pm s, \%)$.

\begin{tabular}{llll}
\hline Groups & $\mathbf{1}$ week & $\mathbf{2}$ weeks & 4 weeks \\
\hline Sham-operation & $97.63 \pm 3.41$ & $101.27 \pm 4.40$ & $102.11 \pm 4.31$ \\
\hline
\end{tabular}

\begin{tabular}{llll}
\hline Model & $8.71 \pm 1.20^{\mathrm{a}}$ & $6.16 \pm 1.01^{\mathrm{ae}}$ & $3.60 \pm 0.76^{\mathrm{aef}}$ \\
\hline Low-dose & $38.57 \pm 2.01^{\mathrm{ab}}$ & $46.27 \pm 2.55^{\mathrm{abe}}$ & $59.54 \pm 3.88^{\mathrm{abef}}$ \\
\hline Middle-dose & $52.00 \pm 2.05^{\mathrm{abc}}$ & $65.74 \pm 3.11^{\mathrm{abce}}$ & $81.10 \pm 2.61^{\mathrm{abcef}}$ \\
\hline
\end{tabular}


Preliminary exploration on the therapeutic effect of AGGF1 in mice with lower limb ischemia and corresponding molecular mechanism

\begin{tabular}{llll}
\hline High-dose & $43.75 \pm 3.70^{\text {abcd }}$ & $\begin{array}{l}54.09 \\
3.06^{\text {abcde }}\end{array}$ & $\pm 66.37 \pm 4.08^{\text {abcdef }}$ \\
\hline$F$ & $F_{\text {groups }}=25.307$ & $F_{\text {time }}=16.248$ & $F_{\text {interaction }}=20.079$ \\
\hline$P$ & $P_{\text {groups }}=0.000$ & $P_{\text {time }}=0.000$ & $P_{\text {interaction }}=0.000$ \\
\hline
\end{tabular}

Note: Compared with sham-operation group, ap<0.05; Compared with model group, ${ }^{b} \mathrm{P}<0.05$; Compared with low-dose group, ${ }^{\mathrm{C}} \mathrm{P}<0.05$; Compared with middle-dose, ${ }^{\mathrm{d}} \mathrm{P}<0.05$; Compared with 1 week, e $\mathrm{P}<0.05$; Compared with 2 week, ${ }^{\mathrm{f}} \mathrm{P}<0.05$

Table 3. Comparison of AGGF1, HIF-1 $\alpha$, and VEGF mRNA levels in the musculus gastrocnemius among different groups $(\bar{x} \pm s)$.

\begin{tabular}{llll}
\hline Groups & AGGF1 mRNA & HIF-1 $a$ mRNA & VEGF mRNA \\
\hline Sham-operation & $0.81 \pm 0.07$ & $0.67 \pm 0.06$ & $0.81 \pm 0.05$ \\
\hline Model & $0.89 \pm 0.06^{\mathrm{a}}$ & $0.76 \pm 0.07^{\mathrm{a}}$ & $0.93 \pm 0.06^{\mathrm{a}}$ \\
\hline Low-dose & $0.98 \pm 0.07^{\mathrm{ab}}$ & $0.90 \pm 0.08^{\mathrm{ab}}$ & $1.02 \pm 0.09^{\mathrm{ab}}$ \\
\hline Middle-dose & $1.39 \pm 0.11^{\mathrm{abc}}$ & $1.23 \pm 0.12^{\mathrm{abc}}$ & $1.38 \pm 0.13^{\mathrm{abc}}$ \\
\hline High-dose & $1.18 \pm 0.10^{\mathrm{abcd}}$ & $1.04 \pm 0.11^{\mathrm{abcd}}$ & $1.16 \pm 0.11^{\mathrm{abcd}}$ \\
\hline $\mathrm{F}$ & 62.141 & 48.068 & 44.769 \\
\hline $\mathrm{P}$ & 0 & 0 & 0
\end{tabular}

Note: Compared with sham-operation group, ap<0.05; Compared with model group, ${ }^{\mathrm{b}} \mathrm{P}<0.05$; Compared with low-dose group, ${ }^{\mathrm{C}} \mathrm{P}<0.05$; Compared with middle-dose, ${ }^{\mathrm{d}} \mathrm{P}<0.05$.

Table 4. Comparison of AGGF1, HIF-1 $\alpha$, and VEGF proteins in the musculus gastrocnemius among different groups $(\bar{x} \pm s)$.

\begin{tabular}{llll}
\hline Groups & AGGF1 & HIF-1a & VEGF \\
\hline Sham-operation & $0.56 \pm 0.07$ & $0.42 \pm 0.08$ & $0.45 \pm 0.07$ \\
\hline Model & $0.73 \pm 0.12^{\mathrm{a}}$ & $0.68 \pm 0.09^{\mathrm{a}}$ & $0.56 \pm 0.06^{\mathrm{a}}$ \\
\hline Low-dose & $0.97 \pm 0.11^{\mathrm{ab}}$ & $0.94 \pm 0.12^{\mathrm{ab}}$ & $0.74 \pm 0.09^{\mathrm{ab}}$ \\
\hline Middle-dose & $1.55 \pm 0.13^{\mathrm{abc}}$ & $1.25 \pm 0.11^{\mathrm{abc}}$ & $0.96 \pm 0.08^{\mathrm{abc}}$ \\
\hline High-dose & $1.26 \pm 0.12^{\mathrm{abcd}}$ & $1.12 \pm 0.10^{\mathrm{abcd}}$ & $0.87 \pm 0.07^{\mathrm{abcd}}$ \\
\hline $\mathrm{F}$ & 101.518 & 88.173 & 64.129 \\
\hline $\mathrm{P}$ & 0 & 0 & 0 \\
\hline
\end{tabular}

Note: Compared with sham-operation group, ap $<0.05$; Compared with model group, bP $<0.05$; Compared with low-dose group, ${ }^{\mathrm{C}} \mathrm{P}<0.05$; Compared with middle-dose, ${ }^{\mathrm{d}} \mathrm{P}<0.05$.

\section{Recovery percentage of lower limb bloodstream}

Statistically significant differences were found in the recovery percentage of lower limb bloodstream among different groups at different time points and interaction comparison $(\mathrm{P}<0.05)$. The sham-operation group achieved the highest recovery percentage of lower limb bloodstream after 1, 2 and 4 weeks of treatment, followed by the middle-dose, high-dose, low-dose, and model groups successively. Statistically significant differences were observed between any two groups $(\mathrm{P}<0.05)$. With respect to intra-group comparison, the sham-operation group showed no significant changes $(\mathrm{P}>0.05)$. The recovery percentage of lower limb bloodstream of the three dose groups

increased as time passed $(\mathrm{P}<0.05)$, whereas that of the model group dropped dramatically $(\mathrm{P}<0.05)$. The results are shown in Table 2.

\section{AGGF1, HIF-1 $\alpha$, and VEGF mRNA levels in the musculus gastrocnemius}

Different groups showed statistically significant differences in AGGF1, HIF-1 $\alpha$, and VEGF mRNA levels in the musculus gastrocnemius $(\mathrm{P}<0.05)$. The sham-operation group exhibited the lowest AGGF1, HIF-1 $\alpha$, and VEGF mRNA levels, followed by the middle-dose, high-dose, low-dose, and model groups successively. Statistically significant differences were found between any two groups $(\mathrm{P}<0.05)$. The results are shown in Table 3.

\section{AGGF1, HIF-1 $\alpha$, and VEGF protein levels in the musculus gastrocnemius}

Statistically significant differences in AGGF1, HIF-1 $\alpha$, and VEGF protein levels in the musculus gastrocnemius were observed among different groups $(\mathrm{P}<0.05)$. The shamoperation group exhibited the lowest AGGF1, HIF-1 $\alpha$, and VEGF protein levels in the musculus gastrocnemius, followed by the middle-dose, high-dose, low-dose, and model groups successively. Statistically significant differences were found between any two groups $(\mathrm{P}<0.05)$. The results are shown in Figure 1 and Table 4.

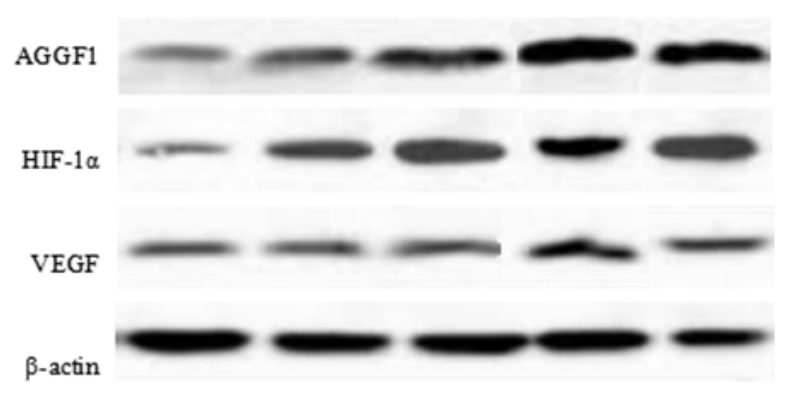

Figure 1. Western blot mapping of AGGF1, HIF-1 $\alpha$, and VEGF proteins in the musculus gastrocnemius. Note: Sham-operation model, Low-dose, Middle-dose, High-dose.

\section{Discussion}

This study discovered that the sham-operation group had the lowest tissue necrosis and dyskinesia scores throughout the test period, followed by the middle-dose, high-dose, low-dose, and model groups successively. Statistically significant differences were observed between any two groups $(\mathrm{P}<0.05)$, and intragroup comparison revealed a slight change in the tissue necrosis score of the sham-operation group $(\mathrm{P}>0.05)$. The dyskinesia scores of the sham-operation and the three dose groups sharply dropped as time passed $(\mathrm{P}<0.05)$, indicating that different AGGF1 concentrations can significantly improve tissue necrosis and dyskinesia of mice with lower limb ischemia [4]. The middle-dose group achieved the most outstanding therapeutic effect. Although the sham-operation group exhibited certain dyskinesia caused by the operative 
wound, such dyskinesia will gradually recover as time passes. This study also discovered that the sham-operation group achieved the highest recovery percentage of lower limb bloodstream at different time points, followed by the middledose, high-dose, low-dose, and model groups successively. Statistically significant differences between any two groups were found $(\mathrm{P}<0.05)$. Intra-group comparison revealed that the recovery percentage of lower limb bloodstream in the three dose groups sharply increased as time passed $(\mathrm{P}<0.05)$, whereas that of the model group sharply dropped $(\mathrm{P}<0.05)$. This finding indicates that different AGGF1 concentrations can accelerate the recovery of lower limb bloodstream, with the middle-dose group showing the best improvement [5]. In this study, laser Doppler detection allowed the discovery of abundant new vessels surrounding the ligation points of the ischemic limb after muscular AGGF1 injection in mice with lower limb ischemia, which achieved good recovery. Abnormal $A G G F 1$ gene expression can cause a dysfunction of the veins and blood capillaries of patients. AGGF1 carries an FHA, Gpatch, and several functional structural domains, which participate in the regulation of endothelial proliferation, growth, and apoptosis [6].

This study also disclosed that the model group and three dose groups exhibited higher AGGF1, HIF-1 $\alpha$, and VEGF mRNA levels in the musculus gastrocnemius compared with the shamoperation group $(\mathrm{P}<0.05)$. The AGGF1, HIF-1 $\alpha$, and VEGF mRNA levels in the musculus gastrocnemius of the three dose groups were significantly higher than those of the model group $(\mathrm{P}<0.05)$. These findings reflect that AGGF1 eukaryotic expression vector can increase AGGF1, HIF-1 $\alpha$, and VEGF mRNA levels in the musculus gastrocnemius of mice with lower limb ischemia [7,8]. In this study, cells at the wound of mice with lower limb ischemia were in an oxygen-deficient environment, which might be one of the reasons for the upregulated HIF-1 $\alpha$ expression. The special structural type of amino terminal in HIF- $1 \alpha$ is an essential structure that combines with DNA [9]. It plays an important role in nuclear localization signal and transcriptional activation. VEGF is another important specificity regulatory factor in neovascularization. It mainly enhances the transparency of blood vessels and plasmexhidrosis through combination with VEGF specificity receptor and a series of regulatory mechanisms, such as phosphatidylinositol 3-kinase and activator protein kinase $\mathrm{B}$, thus inducing vascular endothelial cell division and proliferation [10]. Exogenous AGGF1 injection might activate a series of relative downstream proteins by mediating the HIF/VEGF signaling pathway, thus promoting blood vessel endothelium growth.

\section{Conclusion}

In summary, AGGF1 can improve tissue necrosis and dyskinesia in mice with lower limb ischemia; accelerate bloodstream recovery of lower limbs, and exhibits outstanding therapeutic effect in mice with lower limb ischemia. The corresponding mechanism might be that AGGF1 activates the HIF/VEGF signal transduction pathways, which upregulate the expressions of AGGF1, HIF-1 $\alpha$, and VEGF. The synergistic effect of different factors promotes the recovery of ischemic tissue vessels. Thus, AGGF1 possesses promising application prospects in the treatment of diseases with lower limb ischemia.

\section{References}

1. Tchanque-Fossuo CN, Wishy AM, West KIM, Dawson DL, Dahle SE, Carson JG. Reclaiming autologous amputated tissue for limb salvage of a diabetic foot burn with underlying critical limb ischemia. Adv Skin Wound Care 2018; 31: 596-600.

2. Kalem F, Durmaz S, Ozdemir B, Ergun AG, Ertugrul O. The diagnostic value of procalcitonin, WBC, and CRP in diagnosis of lower respiratory tract infections in elderly patients. Biomed Res-India 2017; 28: 1012-1015.

3. Ren X, Zhou Y, Sun G, Sun X. Protective roles of notoginsenoside $\mathrm{R} 1$ on ischemia/reperfusion injury in isolated rat heart. Lat Am J Pharm 2017; 36: 1680-1687.

4. Gavrilenko AV, Kravchenko AA, Shatalova DV. Secondary reconstructions after endovascular treatment of a woman with critical lower limb ischaemia. Angiol Sosud Khir 2017; 23: 118-121.

5. Bala KR, Raajan NR. An approach for detecting offline intrusive attacks on biomedical information. Biomed ResIndia 2017; 28: 1036-1039.

6. Zhang J, Zhang B, Miao Z, Chu J, Han S. Rutin from buckwheat flowers and leaves exerts vasodilatation and myocardial preservation through inhibiting the elevation of intracellular free calcium concentration. Lat Am J Pharm 2017; 36: 924-930.

7. Gilliland C, Shah J, Martin JG, Miller MJ Jr. Acute limb ischemia. Tech Vasc Interv Radiol 2017; 20: 274-280.

8. Xu W, Zeng S, Li M, Fan Z, Zhou B. Aggf1 attenuates hepatic inflammation and activation of hepatic stellate cells by repressing $\mathrm{Ccl} 2$ transcription. J Biomed Res 2017; 31 : 428-436.

9. Xu W, Zeng S, Li M, Fan Z, Zhou B. Aggfl attenuates hepatic inflammation and activation of hepatic stellate cells by repressing $\mathrm{Ccl} 2$ transcription. J Biomed Res 2016; 31: $1-9$.

10. Shao J, Zeng S, Zhou B, Xu H, Bian Y, Xu Y. Angiogenic factor with $G$ patch and FHA domains 1 (Aggf1) promotes hepatic steatosis in mice. Biochem Biophys Res Commun 2017; 482: 134-140.

\section{*Correspondence to}

Yuehong Zheng

Department of Vascular Surgery

Peking Union Medical College Hospital

Peking Union Medical College and Chinese Academy of Medical Sciences

PR China 